\title{
Cardiovascular, renal and liver events associated with human immunodeficiency virus type I infection and antiretroviral therapy
} Eric S Daar

Address: Division of HIV Medicine, Los Angeles Biomedical Research Institute at Harbor-UCLA Medical Center, Los Angeles, CA 90502, USA

Email: edaar@labiomed.org

FI000 Medicine Reports 2009, I:43 (doi:10.34I0/MI-43)

The electronic version of this article is the complete one and can be found at: http://FI000.com/Reports/Medicine/content/I/43

\begin{abstract}
The first 15 years of the human immunodeficiency virus type I epidemic was characterized by patients progressing to clinical acquired immunodeficiency syndrome and death. The availability of potent antiretrovirals led to the recognition of unique adverse events associated with select drugs. More recent data suggest that end-organ damage may be associated with ongoing viremia. Further understanding of the potential role different drugs and the virus itself has on various organs can enhance the clinician's ability to manage patients in the clinic.
\end{abstract}

\section{Introduction and context}

Prior to the availability of potent antiretroviral (ARV) therapy, human immunodeficiency virus type 1 (HIV-1) infection was notable for the inevitable progression to acquired immunodeficiency syndrome (AIDS)-defining events and death. With the advent of mono- and dualnucleoside reverse transcriptase inhibitor (NRTI) therapy, there was recognition of diverse drug-related adverse events. The introduction of combination ARV therapy with dual NRTIs plus protease inhibitors (PIs) was associated with a dramatic decline in AIDS and mortality, along with an increased appreciation for the development of diverse metabolic complications, such as insulin resistance and dyslipidemia, as well as more recent reports actually showing evidence of premature cardiovascular disease [1]. In addition, co-morbid conditions such as renal and hepatic disease increasingly influenced the quality of the lives of HIV-1-infected individuals. Over the ensuing years research has attempted to define the potential role that select ARV agents and HIV-1 infection itself have on hepatic, renal, and cardiovascular disease.

\section{Recent advances}

Cardiovascular disease

Numerous factors are known to be associated with increased risk of atherosclerotic disease, such as diabetes mellitus, hypertension, smoking, family history and dyslipidemia, all of which occur with variable frequency in those with HIV-1 infection. As combination ARV therapy allowed HIV-1-infected individuals to live longer, these common causes of mortality have become an increasing problem in the HIV clinic. Moreover, concerns are enhanced by the association between select ARV agents and insulin resistance, dyslipidemia and fat maldistribution, along with case reports of premature cardiovascular disease [1]. While there is little evidence clearly demonstrating an association between any specific drug and visceral adiposity, lipoatrophy does appear to be a HIV-1-specific condition primarily linked to the use of thymidine analogues such as zidovudine and stavudine [2]. Similarly, it is now clear that lipid abnormalities have been seen with select NRTIs, nonNRTIs, and PIs. In fact, there are specific guidelines for the management of dyslipidemia in HIV-1-infected individuals $[3,4]$.

While several studies have reported a relationship between ARV use and cardiovascular events, the D:A:D (Data Collection on Adverse Events of Anti-HIV Drugs) cohort is the largest longitudinal study specifically designed to address this question. This study has provided the best evidence that there is an independent 
relationship between duration of combination ARV therapy and cardiovascular events [5], with most of the effect initially being linked to the use of PIs [6]. More recent analyses of this cohort have addressed the relationship between NRTI use and cardiovascular disease. Here they showed that the recent use of abacavir and, to a lesser extent, didanosine was associated with increased risk of cardiac events when compared to regimens that did not use these drugs [7]. Notably the absolute risk was small for all groups and was most prominent amongst those with other cardiovascular risk factors. A follow-up analysis presented at the $16^{\text {th }}$ Conference on Retroviruses and Opportunistic Infections showed that there was also an independent association between cardiovascular events and the use of lopinavir/ritonavir and indinavir, while no such relationship was seen with tenofovir disoproxil fumarate (tenofovir DF) or the non-NRTIs efavirenz and nevirapine [8]. It is important to note that while cohorts can include large numbers of longitudinally followed patients, they are not randomized controlled trials and therefore have numerous limitations. That being said, a similar association between abacavir use and cardiovascular events was recently reported from the SMART (Strategies for Management of Anti-Retroviral Therapy) study [9] and a case control study of patients in the ANRS (National Agency for AIDS Research) French Hospital cohort [10]. Nevertheless, questions remain since there has been no definitive biological explanation given for these findings and other studies have not demonstrated such associations [11].

Intriguing data have recently emerged to suggest a relationship between ongoing viremia and cardiovascular disease [12]. Data from the SMART study, designed to assess whether treatment interruption in those with higher levels of $\mathrm{CD} 4^{+} \mathrm{T}$ cells could minimize some of the toxicity associated with ARV therapy, actually showed overall increased risk of several non-AIDS events, including cardiovascular, renal and hepatic disease, amongst those that interrupted treatment [13]. Further analyses from the SMART study have demonstrated that markers of inflammation, such as interleukin-6 (IL-6), and coagulation, such as D-dimers, are increased in those off ARV therapy, all of these markers having been shown in other populations to be associated with increased risk of cardiovascular events [14]. These findings have been corroborated in another cohort of patients undergoing ARV treatment interruption [15]. Stored samples from the SMART study have further been used to link these changes in markers of inflammation with abacavir use. In a cross-sectional analysis of patients either on or off abacavir at baseline, the investigators showed increased levels of high sensitivity C-reactive protein and IL-6 in those on abacavir compared to those not taking this drug [9]. However, another study showed different results, demonstrating that related markers declined to a similar extent in both arms in a randomized controlled trial comparing tenofovir DF/emtricitabine to abacavir/lamivudine [16]. These differences may reflect the difficulty in observing a potentially modest relationship between select ARV agents and markers of inflammation in the face of the overwhelming influence that suppressing plasma HIV-1 RNA has on these same measures. While results are inconclusive, other potential markers associated with increased cardiovascular disease have also been evaluated as explanations for the possible relationship between select ARV agents and cardiovascular events, such as endothelial function [17] and platelet aggregation [18]. While there remains considerable uncertainty as to how these various data sets should be interpreted, these observations have led to new research exploring the relationship between HIV-1 replication and potential pathogenic mechanisms for select endorgan events.

\section{Renal disease}

Renal disease is common amongst those with HIV-1 infection and is often multifactorial; possible factors include HIV-1-associated nephropathy and co-morbid conditions such as diabetes mellitus and hypertension, as well as co-infection with hepatitis B and C [19]. Certain ARV drugs have also been associated with nephrotoxicity, such as indinavir, a drug rarely used in the current era that frequently caused nephrolithiasis and occasionally interstitial nephritis. In addition, tenofovir DF has been linked to the development of proximal renal tubular dysfunction. It is clearly recommended that routine monitoring of renal function should occur in all HIV-1-infected patients, with particular attention given to those with co-morbid conditions or taking nephrotoxic drugs [20].

One recent study attempted to define the relationship between renal function, tenofovir DF use, and the degree of plasma HIV-1 RNA suppression. This was a relatively small cohort study showing that those with complete viral suppression on a tenofovir DF-containing regimen actually experienced an increase in glomerular filtration rate. In contrast, there was a small but significant decline in renal function amongst those on tenofovir DF that did not achieve full virologic suppression. The authors hypothesize that ongoing viremia, and perhaps the associated increase in inflammation, could be contributing to these adverse outcomes [21]. Other studies have shown a similar relationship between HIV-1 replication and progression of renal disease [22,23]. 


\section{Hepatic disease}

The overwhelming burden of hepatic disease in HIV1 -infected individuals is related to co-infection with hepatitis B and C [24]. HIV-1 and hepatitis co-infection treatment guidelines provide detailed information about relevant interactions between these chronic viral infections and how co-infection influences the management of each pathogen [25]. There is also an increased risk of hepatic steatosis that may be associated with hyperlipidemia, insulin resistance and select ARV agents [26]. Several ARVs have also been shown to result in hepatotoxicity, the strongest links being with high-dose ritonavir, rarely used in the current treatment era, and tipranavir and nevirapine, the latter being in association with immunologic reactions that can be minimized by avoiding use in men with $>400 \mathrm{CD}^{+}$T-cells $/ \mu \mathrm{L}$ and women with $>250 \mathrm{CD}^{+}{ }^{+} \mathrm{T}$ cells $/ \mu \mathrm{L}$ [27]. There have been a few case reports of significant hepatotoxicity with the CCR5 antagonist maraviroc, but this has not been clearly seen in the pivotal randomized controlled trials [28]. While there was some increased risk of hepatotoxicity associated with treatment interruption in the SMART study [13], there are currently much fewer data linking ongoing HIV-1 replication to liver abnormalities than what has been described for cardiovascular and renal disease.

\section{Implications for clinical practice}

There are currently many ARV options available to patients living with HIV-1 disease. A thorough understanding of the relationship between different drugs and various adverse events is critical to the optimal management of such patients. The first step towards safely using any medication is to know what conditions any given individual is predisposed to, to understand the safety profile of each drug, and to monitor for adverse events. In the case of cardiovascular disease it is important to emphasize efforts to modify known risk factors and to monitor and manage dyslipidemia [4]. When lipid abnormalities are present, clinicians should be aware of how different medications may be contributing to these problems and should consider changes in therapy when appropriate. The emerging data linking select drugs to cardiovascular disease, while not definitive, should also be considered when making any clinical decision, particularly in those with other risk factors. Similar considerations apply to underlying renal disease, where control of traditional risk factors such as diabetes mellitus and hypertension should be prioritized along with careful monitoring and avoidance of nephrotoxic drugs in those at greatest risk. With regards to liver disease, the best strategy is to diligently screen for hepatitis $\mathrm{B}$ and $\mathrm{C}$ co-infection, minimize use of hepatotoxic agents and to provide immunization against viral hepatitis when appropriate. In addition, all patients should be carefully monitored for liver disease, with a particular focus on those taking hepatotoxic agents and who are hepatitis B and/or C co-infected.

The recent data linking ongoing HIV-1 replication with cardiovascular disease, and possibly renal disease, are provocative, and the association remains an area of increasing investigation. Clinicians should be aware of these studies, their potential implications with regards to the use of ARV therapy, and how these findings might support the earlier initiation of treatment in a given individual. However, this needs to be balanced by the fact that the studies remain preliminary and the results thus far have been mostly hypothesis generating. Furthermore, decisions regarding the timing of treatment must be made in the context of the specific patient to be treated as well as the overall costs and known risks associated with the use of ARV therapy.

\section{Abbreviations}

AIDS, acquired immunodeficiency syndrome; ANRS, Agence Nationale de Recherches sur le Sida et les Hépatites Virales (National Agency for AIDS Research); ARV, antiretroviral; D:A:D, Data Collection on Adverse Events of Anti-HIV Drugs; HIV-1, human immunodeficiency virus type 1; IL, interleukin; NRTI, nucleoside reverse transcriptase inhibitor; PI, protease inhibitor; SMART, Strategies for Management of Anti-Retroviral Therapy; tenofovir DF, tenofovir disoproxil fumarate.

\section{Competing interests}

ED received research support from Abbott, GlaxoSmithKline and Merck. He is a scientific consultant for Abbott, Bristol Myers Squibb, Gilead, GlaxoSmithKline, Merck, Pfizer, Schering Plough, Pathway, Tibotec and serves on a Data Safety Monitoring Board for Ardea Biosciences.

\section{Acknowlegements}

ED receives grant support from California HIV Research Program (grant CH05-SD-607-005), and National Institutes of Health (NIH) (grants AI069424 and M01RR00424).

\section{References}

I. Henry K, Melroe H, Huebsch J, Hermundson J, Levine C, Swensen L, Daley J: Severe premature coronary artery disease with protease inhibitors. Lancet 1998, 351:1328.

2. Bacchetti P, Gripshover B, Grunfeld C, Heymsfield S, McCreath H, Osmond D, Saag M. Scherzer R, Shlipak M. Tien P; Study of Fat Redistribution and Metabolic Change in HIV Infection (FRAM): Fat distribution in men with HIV infection. J Acquir Immune Defic Syndr 2005, 40:|2|-31.

3. Wohl DA, McComsey G, Tebas P, Brown TT, Glesby MJ, Reeds D, Shikuma C, Mulligan K, Dube M, Wininger D, Huang J, Revuelta M, Currier J, Swindells S, Fichtenbaum C, Basar M, Tungsiripat M, 
Meyer W, Weihe J, Wanke C: Current concepts in the diagnosis and management of metabolic complications of HIV infection and its therapy. Clin Infect Dis 2006, 43:645-53.

4. Dubé MP, Stein JH, Aberg JA, Fichtenbaum CJ, Gerber JG, Tashima KT, Henry WK, Currier JS, Sprecher D, Glesby MJ; Adult AIDS Clinical Trials Group Cardiovascular Subcommittee; HIV Medical Association of the Infectious Disease Society of America: Guidelines for the evaluation and management of dyslipidemia in human immunodeficiency virus (HIV)-infected adults receiving antiretroviral therapy: recommendations of the HIV Medical Association of the Infectious Disease Society of America and the Adult AIDS Clinical Trials Group. Clin Infect Dis 2003, 37:613-27.

5. Friis-Møller N, Sabin CA, Weber R, d'Arminio Monforte A, El-Sadr WM, Reiss P, Thiébaut R, Morfeldt L, De Wit S, Pradier C, Calvo G, Law MG, Kirk O, Phillips AN, Lundgren JD; Data Collection on Adverse Events of Anti-HIV Drugs (DAD) Study Group: Combination antiretroviral therapy and the risk of myocardial infarction. N Engl J Med 2003, 349:1993-2003.

6. DAD Study Group, Friis-Møller N, Reiss P, Sabin CA, Weber R, Monforte A, El-Sadr W, Thiébaut R, De Wit S, Kirk O, Fontas E, Law MG, Phillips A, Lundgren JD: Class of antiretroviral drugs and the risk of myocardial infarction. N Engl J Med 2007, 356: 1723-35.

FI000 Factor 6.0 Must Read Evaluated by Eric Daar 09 May 2007

7. D:A:D Study Group, Sabin CA, Worm SW, Weber R, Reiss P, ElSadr W, Dabis F, De Wit S, Law M, D’Arminio Monforte A, FriisMøller N, Kirk O, Pradier C, Weller I, Phillips AN, Lundgren JD: Use of nucleoside reverse transcriptase inhibitors and risk of myocardial infarction in HIV-infected patients enrolled in the D:A:D study: a multi-cohort collaboration. Lancet 2008, 37I: 1417-26.

8. Lundgren J, Reiss P, Worm S, Weber R, El-Sadr W, De Wit S, Law M, d'Arminio Monforte A, Pradier C, Sabin C; Aquataine, AHOD, ATHENA, INSIGHT, EuroSIDA, ICONA, Nice, SHCS, St Pierre Cohorts, D:A:D Study Group: Risk of myocardial infarction with exposure to specific ARV from the PI, NNRTI, and NRTI drug classes: The D:A:D Study. 16th Conference on Retroviruses and Opportunistic Infections: February 8-I I, 2009; Montreal, Canada. Abstract 44LB. [http://www.retroconference.org/2009/Abstracts/ 36644.htm].

9. Strategies for Management of Anti-Retroviral Therapy/INSIGHT; DAD Study Groups: Use of nucleoside reverse transcriptase inhibitors and risk of myocardial infarction in HIV-infected patients. AIDS 2008, 22:FI7-24.

10. Lang S, Mary-Krause M, Cotte L, Gilquin J, Partisani M, Simon A, Boccara F, Costagliola D; the Clinical Epi Group of the French Hosp Database on HIV: Impact of specific NRTI and PI exposure on the risk of mycoardial infaction: a case-control study nested within FHDH ANRS CO4. 16th Conference on Retroviruses and Opportunistic Infections: February 8-II, 2009; Montreal, Canada. Abstract 43LB. [http://www.retroconference.org/2009/Abstracts/ 36525.htm].

II. Benson C, Ribaudo H, Zheng E, Koletar S, Smurzynski M, Bosch R, Bastow B, Collier A, Schouten J; ACTG A500I/ALLRT Protocol Team: No association of abacavir use with risk of myocardial infarction or severe cardiovascular disease events: Results from ACTG A500I. 16th Conference on Retroviruses and Opportunistic Infections: February 8-1I, 2009; Montreal, Canada. Abstract 72I. [http://www.retroconference.org/2009/Abstracts/ 34820.htm].

12. van Vonderen MG, Smulders $Y M$, Stehouwer CD, Danner SA, Gundy CM, Vos F, Reiss P, Agtmael MA: Carotid intima-media thickness and arterial stiffness in HIV-infected patients: the role of HIV, antiretroviral therapy, and lipodystrophy. J Acquir Immune Defic Syndr 2009, 50:I53-6I.

13. Strategies for Management of Antiretroviral Therapy (SMART) Study Group, El-Sadr WM, Lundgren JD, Neaton JD, Gordin F, Abrams D, Arduino RC, Babiker A, Burman W, Clumeck N, Cohen CJ, Cohn D, Cooper D, Darbyshire J, Emery S, Fätkenheuer G, Gazzard B,
Grund B, Hoy J, Klingman K, Losso M, Markowitz N, Neuhaus J, Phillips A, Rappoport C: CD4+ count-guided interruption of antiretroviral treatment. N Engl J Med 2006, 355:2283-96.

Changes Clinical Practice

FI000 Factor 6.0 Must Read

Evaluated by Paul Volberding 26 Jan 2007

14. Kuller LH, Tracy R, Belloso W, De Wit S, Drummond F, Lane HC, Ledergerber B, Lundgren J, Neuhaus J, Nixon D, Paton NI, Neaton JD; INSIGHT SMART Study Group: Inflammatory and coagulation biomarkers and mortality in patients with HIV infection. PLoS Med 2008, 5:e203.

FI000 Factor 6.0 Must Read

Evaluated by Eric Daar 08 Jan 2009

15. Papasavvas E, Azzoni L, Pistilli M, Hancock A, Reynolds G, Gallo C, Ondercin J, Kostman JR, Mounzer K, Shull J, Montaner LJ: Increased soluble vascular cell adhesion molecule-I plasma levels and soluble intercellular adhesion molecule-I during antiretroviral therapy interruption and retention of elevated soluble vascular cellular adhesion molecule-I levels following resumption of antiretroviral therapy. AIDS 2008, 22:| I53-6I.

16. McComsey G, Smith K, Patel P, Bellos N, Sloan L, Lackey P, Kumar P, Sutherland-Phillips D, Yau L, Shaefer M: Similar reductions in markers of inflammation and endothelial activation after initiation of abacavir/lamivudine or tenofovir/emtricitabine: The HEAT Study. 16th Conference on Retroviruses and Opportunistic Infections: February 8-II, 2009; Montreal, Canada. Abstract 732. [http://www.retroconference.org/2009/Abstracts/36331.htm].

17. Hsue P, Wu Y, Schnell A, Ganz P, Hunt P, Hatano H, Martin J, Deeks S: Association of abacavir and HIV disease factors with endothelial function in patients on long-term suppressive ART. 16th Conference on Retroviruses and Opportunistic Infections: February 8-II, 2009; Montreal, Canada. Abstract 723. [http://www. retroconference.org/2009/Abstracts/33690.htm]

18. Satchell C, O'Connor E, Peace A, Cotter A, Sheehan G, Tedesco T, Doran P, Powderly W, Kenny D, Mallon P: Platelet hyperreactivity in HIV-I-infected patients on abacavir-containing ART. 16th Conference on Retroviruses and Opportunistic Infections: February 8-II, 2009; Montreal, Canada. Abstract I5ILB [http://www. retroconference.org/2009/Abstracts/36730.htm]

19. Kalim S, Szczech LA, Wyatt CM: Acute kidney injury in HIVinfected patients. Semin Nephrol 2008, 28:556-62.

20. Gupta SK, Eustace JA, Winston JA, Boydstun II, Ahuja TS, Rodriguez RA, Tashima KT, Roland M, Franceschini N, Palella F], Lennox JL, Klotman PE, Nachman SA, Hall SD, Szczech LA: Guidelines for the management of chronic kidney disease in HIVinfected patients: recommendations of the HIV Medicine Association of the Infectious Diseases Society of America. Clin Infect Dis 2005, 40:1559-85.

21. Guaraldi G, Roverato A, Giovanardi C, Ravera F, Squillace N, Orlando G, Cappelli G, Esposito R, Palella F: Glomerular filtration rates in HIV-infected patients treated with and without tenofovir: a prospective, observational study. J Antimicrob Chemother 2009, 63:374-9.

22. Choi A, Shlipak M, Hunt P, Martin J, Deeks S: HIV-infected persons continue to lose kidney function despite successful ART. 16th Conference on Retroviruses and Opportunistic Infections: February 8-II, 2009; Montreal, Canada. Abstract 38. [http://www. retroconference.org/2009/Abstracts/35060.htm].

23. Mocroft A, Wyatt C, Szczech L, Neuhaus J, El-Sadr W, Tracy R, Kuller L, Shlipak M, Angus B, Klinker H, Ross M; INSIGHT SMART Study Group: Interruption of antiretroviral therapy is associated with increased plasma cystatin C. AIDS 2009, 23:7I-82.

24. Sulkowski MS: Management of hepatic complications in HIVinfected persons. J Infect Dis 2008, 197:S279-93.

25. Rockstroh JK, Bhagani S, Benhamou Y, Bruno R, Mauss S, Peters L, Puoti M, Soriano V, Tural C; EACS Executive Committee: European AIDS Clinical Society (EACS) guidelines for the clinical management and treatment of chronic hepatitis B and C coinfection in HIV-infected adults. HIV Med 2008, 9:82-8. 
26. Sulkowski MS, Mehta SH, Torbenson M, Afdhal NH, Mirel L, Moore RD, Thomas DL: Hepatic steatosis and antiretroviral drug use among adults coinfected with HIV and hepatitis C virus. AIDS 2005, 1 9:585-92

27. Núñez M: Hepatotoxicity of antiretrovirals: incidence, mechanisms and management. J Hepatol 2006, 44:SI32-9.
28. Gulick RM, Lalezari J, Goodrich J, Clumeck N, Dejesus E, Horban A, Nadler J, Clotet B, Karlsson A, Wohlfeiler M, Montana JB, McHale M, Sullivan J, Ridgway C, Felstead S, Dunne MW, van der Ryst E, Mayer H; MOTIVATE Study Teams: Maraviroc for previously treated patients with R5 HIV-I infection. N Engl J Med 2008, 359:|429-4|. 